\title{
A experiência social e escolar dos jovens do Ensino Secundário: contributos de um estudo sociológico
}

Maria Cecília Pereira dos Santos*

\section{Resumo}

Este artigo, em primeiro lugar, discute algumas perspectivas defendidas por certos autores acerca dos jovens alunos do Ensino Secundário, com o objectivo de se chegar à compreensão e à problematização da experiência social juvenil. Em segundo lugar, ainda que sumariamente, toma em consideração alguns conceitos e estudos sobre a experiência social e escolar dos jovens, realçando a aprendizagem do ofício de aluno. Finalmente, apresenta alguns dados empíricos que traduzem certas dimensões da experiência social e escolar dos jovens alunos

Palavras-chave: Experiência social. Experiência escolar. Alunos. Ofício de aluno.

\section{The social and school experience of young secondary school students: an approach about a sociological research \\ Abstract}

First, this article discusses some perspectives argued by certain authors about young secondary school students in order to comprehend and question the social experience. Secondly, the article summarily takes in consideration concepts and some studies about the social and school experience, highlighting the apprenticeship of the student work. Finally, a relevant amount of empirical data is systematised based on the practice of the inquired young people upon social and school experience.

Keywords: Social experience. School experience. Students. Student work.

Doutora em Educação; docente convidada, Mestrado em Educação, Universidade do Minho, Braga, PT.

E-mail: cecilia_santos@netcabo.pt 


\section{La experiencia social y escolar de los jóvenes de la Enseñanza Secundaria: contribuciones de un estudio sociológico Resumen}

Este artículo, en primer lugar, discute algunas perspectivas defendidas por ciertos autores sobre los jóvenes alumnos de la Enseñanza Secundaria, con el objetivo de llegar a la comprensión y a la problematización de la experiencia social juvenil. En segundo lugar, aunque brevemente, considera algunos conceptos y estudios sobre la experiencia social y escolar de los jóvenes destacando el aprendizaje del oficio del alumno. Finalmente, presenta algunos datos empíricos que traducen ciertas dimensiones de la experiencia social y escolar de dichos jóvenes alumnos. Palabras clave: Experiencia social. Experiencia escolar. Oficio del alumno

\section{Introdução}

Este artigo, que agora se apresenta, decorre da realização de um trabalho académico no âmbito de um projecto de Doutoramento em Educação, na Área de Conhecimento em Sociologia da Educação.

Esse estudo privilegiou a metodologia qualitativa e o grupo de discussão como principal técnica para a recolha da informação ao longo do tempo em que decorreu o trabalho de campo. Os nossos principais interlocutores foram alguns grupos de jovens alunos de Ensino Secundário, cujas reflexões (individual e colectiva) se apresentaram muito favoráveis para a compreensão de diferentes perspectivas sociais e escolares em presença na escola e, ainda, de alguns dos mais recorrentes dilemas com que se deparavam no decurso da sua vida escolar e juvenil.

Assim, neste artigo, a nossa preocupação incide, num primeiro momento, sobre alguns autores e algumas perspectivas acerca dos jovens, no sentido de se chegar à compreensão e à problematização da experiência social juvenil. Num segundo momento, ainda que sumariamente, tomam-se em consideração alguns conceitos e estudos sobre a experiência social e escolar dos jovens realçando-se a aprendizagem do ofício de aluno. Finalmente, sistematizam-se alguns dados empíricos que ilustram algumas dimensões da experiência social e escolar dos jovens alunos.

\section{A experiência social dos jovens: compreender e problematizar}

A procura de sentidos para a compreensão da experiência social dos jovens remete-nos para diferentes autores e para perspectivas sociológicas da vida quotidiana que elegem como centro de estudo a decifração da actividade social dos 
indivíduos, dos seus comportamentos em sociedade, das interacções que tecem com os outros descrevendo e interpretando as relações sociais do(s) quotidiano(s).

Em França, por exemplo, alguns trabalhos de pesquisa têm vindo a valorizar a perspectiva dos actores, as suas subjectividades, num mundo que não pode prescindir do trabalho dos indivíduos e dos diferentes actores para a criação de uma nova ordem social, para mostrar que as teorias da sociedade são teorias de acção e para construir a noção de experiência social «que designa as condutas individuais e colectivas dominadas pela heterogeneidade dos seus princípios constitutivos, e pela actividade dos indivíduos que devem construir o sentido das suas práticas no seio dessa mesma heterogeneidade» (DUBET; COUSIN; GUILLEMENT, 1994, p. 15).

Alguns trabalhos de autores portugueses, ao longo das três últimas décadas, têm demonstrado também interesse pelos processos de construção de identidades individuais, socioculturais e/ou grupais dos jovens através da sua experiência social. Deste modo, alguns estudos acentuam e procuram realçar a juventude como uma realidade social criada pelas modernas sociedades (CRUZ et al., 1984); outros mostram o (des)interesse da participação dos jovens em diferentes dimensões, ou seja, quer ao nível da gestão das escolas secundárias (LIMA, 1988), quer ao nível das estruturas partidárias de juventude (CRUZ, 1990), quer tendo em linha de conta as implicações de variáveis sócio-econômicas na participação (SANTOS, 1991), ou, ainda, caracterizando a participação dos jovens nos processos eleitorais nas escolas secundárias (LIMA, 1988); outros, por seu lado, pretendem compreender a crise que afectou a juventude a partir dos anos 70, à luz da quebra de crescimento económico que arrastou consigo menores oportunidades sociais e a desvalorização dos títulos escolares, (atendendo à discrepância existente entre os diplomas e as características inerentes aos postos de trabalho, a qual arrasta consigo a dependência monetária dos jovens da família) chamando a atenção para alguns aspectos que se prendem com a mudança de uma "socialização de produção" para uma "socialização de consumo" (SCHMIDT,1990; GRÁCI0,1991; PAIS,1991); finalmente, alguns estudos continuam a interessar-se não só pelos modos de vida dos jovens na sua aparente unidade e na transição para a vida activa onde (se)perdem ou (se)acham sentidos desejáveis para os seus projectos de vida pessoal analisando, compreendendo e interpretando os diversos sonhos concretizados ou adiados (PAIS,1990, 1993, 1998, 2001), mas, também, pelas práticas culturais dos jovens de origens e contextos sociais heterogéneos (LOPES, 1996).

Paralelamente, alguns autores privilegiando outros contextos sociais, nomeadamente, Coleman e Húsen (1990) apresentam uma visão histórica da problemática das mutações da sociedade e da passagem para a vida activa dos jovens cruzando algumas variáveis recorrentes em análises que foram sendo realizadas ao longo do tempo (escolarização, economia, trabalho, cultura social, valores, socialização), acabando por incidir sobre alguns problemas que afligem as sociedades actuais, 
(exclusão social e cultural, competição, precariedade de emprego, apatia, subculturas juvenis). Assim, concluem que os jovens "[...] atravessam, após a adolescência, um período durante o qual nada é resolvido, nem sequer a questão do trabalho nem a da familia, uma espécie de compasso de espera antes das responsabilidades da idade adulta" ( COLEMAN; HÚSEN, 1990, p. 13).

A vida quotidiana dos jovens, porém, pode ainda ser pautada por interacções individuais e colectivas heterogéneas em confronto que podem ser observadas e analisadas quando são estudados, por exemplo, os movimentos sociais, a juventude no âmbito da sociologia da experiência.

\section{A experiência social e escolar dos jovens alunos: da vida juvenil à aprendizagem do ofício de aluno}

Em diferentes obras e em diferentes autores francófonos, anglo-saxónicos e de língua castelhana (DUBET, 1991, 1994, 2000, 2004; DUBET; COUSIN; GUILLEMET, 1991; JACKSON, 1992; DUBET; MARTUCCELLI, 1996; MAYORAL, 1996; BARRĖRE, 1997; RAYOU, 1998; ROCHEX, 1998; EVERHART, 1999; POMEROY, 1999; DUBET; DURU-BELLAT, 2000) a temática da experiência escolar tem vindo a ocupar um espaço de relevo nos estudos sobre a escola, e, no caso português, a escola secundária e as vivências dos jovens alunos têm sido privilegiadas em variados estudos e analisadas em diferentes ângulos, nomeadamente, desde a década de oitenta (LIMA, 1988, 1992; AFONSO, 1991, 1995; LOPES, 1996; GOMES, 1998; SILVA,1999; ABRANTES, 2003; GAMA, 2003; TAVARES, 2004; MATOS, 2006a, 2006b).

As obras dos autores franceses suprarreferidos, vocacionadas para a análise do sistema educativo e privilegiando a intervenção sociológica, complementam-se cruzando perspectivas recorrentes, ao mesmo tempo que desvendam e confrontam algumas opiniões relativamente às aprendizagens e às vivências de alguns grupos de jovens. Estes estudos incidem, particularmente, sobre o prisma subjectivo da experiência escolar dos estudantes, definindo-a como "[...] a vertente subjectiva do sistema escolar, mais exactamente, a maneira pela qual os actores representam e constroem para si mesmos este sistema, definindo cada um dos elementos e gerando articulações" (DUBET, 1991, p. 28).

Ora, a análise da vida da organização escolar vai atendendo e reflectindo sobre as acções e interacções plurais que os diferentes actores vão levando a efeito, isto porque, no mesmo espaço físico se podem desenvolver resistências, lutas, acções que, não raras vezes, traduzem algumas desilusões, ambiguidades, exclusões efectivas, ausências, (in)certezas provenientes, a priori, de inúmeras desconexões em presença no contexto escolar e a que alguns grupos de estudantes não deixam de ser sensiveis. 
De facto, o sistema educativo, sendo uma organização social, deverá privilegiar a função de integração (e não de exclusão) que se concretiza, por vezes, através da "capacidade da organização escolar acolher e reconhecer a comunidade e a vida juvenil' (DUBET, 1991, p. 25). Neste sentido, as escolas de Ensino Secundário parecem ser espaços onde (in)visivelmente coexistem, por um lado, dimensões de natureza pessoal e subjectiva e, por outro lado, dimensões de carácter impessoal e objectivo que podem propiciar o encontro triangular entre a cultura escolar, a selecção e a vida juvenil. Embora, outras perspectivas chamem a atenção para o facto de estas três dimensões não serem sempre conciliáveis, até porque a elas se sobrepõem relações de poder assimétricas entre os actores. Aliás, o trabalho paradigmático realizado em finais da década de sessenta, Life in Classrooms, por Phillip Jackson já aludia à questão da problemática das desigualdades de poder na sala de aula articulando-a com a avaliação dos estudantes e suas consequências que

[...] se relacionam com condições mais amplas de liberdade, privilégio e responsabilidade que se manifestam na sala de aula. [De facto, sublinha o autor,] a autoridade do professor é tão prescritiva como restritiva [porque] os professores limitam-se a estabelecer tarefas aos alunos e não se limitam a travar condutas indesejáveis. [Por outro lado] a essência da autoridade do professor radical no domínio da atenção dos alunos, [isto é] a criança na escola deve aprender [...] a olhar e a escutar (JACKSON, 1992, p. 68-70).

Ora, como dá conta um estudo da década de noventa e tal como em décadas passadas, a alguns grupos de estudantes portugueses parece desagradar o modo como o(s) poder(es) dos professores se exerce $(\mathrm{m})$ sobre eles. Deste modo, sempre que surge a oportunidade de se fazerem ouvir acerca da sua experiência escolar, especialmente ao nível da sala de aula, referem o facto de que "os alunos têm de estar atentos, calar e ouvir muito serenamente o que o professor diz. [Assim] a relação entre professores e alunos é uma 'guerra' que não tem limites" (GOMES, 1998, p. 165). Estamos, deste modo, face a uma determinada acção dos alunos que evidencia, por exemplo, o poder informal dos mesmos dentro da organização escolar. Por seu lado, referindo-se ao poder do grupo de alunos na sala de aula, Afonso (1991, p. 143) sublinha que

[...] a principal fonte de poder dos alunos é o grupo [sugerindo que] o poder de um aluno na sala de aula pode avaliar-se pela sua capacidade de mobilizar conjuntos de interacção, mas esta capacidade pode estar associada a outros factores, entre os quais o facto de esse mesmo aluno pertencer, eventualmente, a subculturas específicas, como aquelas que foram caracterizadas em certos estudos como subculturas antiescolares, e que sendo temidas por outros alunos e até por 
professores, podem impor algumas condições na definição da situação da sala de aula. Neste caso estaríamos, indirectamente, em presença do poder de grupo.

Acresce que, um outro estudo chama a atenção para a função de integração ligando-à função de selecção presente no Ensino Secundário e que, consequentemente, o afasta de um sistema perfeitamente integrado, visto que

[...] o modelo cultural não tem unidade e a sua acção educativa é por vezes indefinida. [E, cada vez mais, ] com a massificação escolar a selecção tem uma importância crescente, embora a utilidade social dos estudos não esteja [à partida] garantida para cada um (DUBET, 1991, p. 28).

Não obstante, a perspectiva deste sociólogo tenta demonstrar que pode existir uma mediação entre a função de selecção e o modelo cultural do sistema escolar processada através de três dimensões: experiência escolar, experiência educativa e estratégia. Esta última, parece estar intrinsecamente ligada ao desempenho de funções, às regras de disciplina, aos modos de selecção, ou seja, ao desenvolvimento de lógicas de adaptação, de integração, onde se cruzam tendências calculistas face aos investimentos escolares e à gestão dos interesses heterogéneos de cada um.

Deste modo, será de realçar que atendendo à evidente função selectiva da escola, o peso desta dimensão assume uma grande relevância na vida escolar dos jovens e no processo de compreensão dos mecanismos do sistema educativo em que estão inseridos, o que pode estar na origem das preocupações da generalidade destes actores em aprender a sobreviver, a interiorizar o que Philippe Perrenoud chamou de ofício de aluno, à medida que se vão apercebendo de o quê, quando e como fazer para chegar ao sucesso escolar.

Para esta perspectiva, os alunos condenados a "estratégias de pobre", aprendem a viver descobrindo e desenvolvendo acções estratégicas "essencialmente defensivas, que consistem em jogar com as regras, em contorná-las, a escapar-se-lhes ou a negociarem a sua aplicação caso a caso» (PERRENOUD, 1995, p.120)'1.

\section{Selecção e avaliação: contributos de uma pesquisa}

Quando procedemos ao nosso trabalho de terreno (ao longo de dois anos lectivos, 2003-2004 e 2004-2005), optando por um estudo qualitativo que privilegiou

\footnotetext{
A este propósito José A. Correia (1998, p. 113) refere que foi a partir dos anos 80 que o aluno como actor entrou no discurso sociológico e que "o 'oficio de aluno' é, assim, construído na aprendizagem informal de regras também elas informais que, ao mesmo tempo que devem ser aceites, admitem uma 'margem' de transgressão estratégica, ou seja, admitem a possibilidade da sua transgressão por actores que ao fazê-lo se mantêm nas regras do jogo".
} 
para a recolha da informação a técnica do grupo de discussão, encetámos um percurso que permitiu dar voz a alguns jovens do Ensino Secundário (Curso Geral e Curso Tecnológico). A propósito de várias dimensões que atravessavam os seus quotidianos, sobretudo a da selecção escolar, várias perspectivas foram sendo cruzadas e com ela relacionadas, o que permitiu identificar a existência de um ofício de aluno. Deste modo, as suas análises recaíram sobre o modelo de avaliação que privilegiava os testes (avaliação interna) e os exames nacionais (avaliação externa) e que parecia acentuar os quotidianos feitos de stress e de crises pessoais. Algumas dessas crises foram vistas como consequência imediata da falta de tempo para se poder ser jovem e manter uma vida social para além da escola, "[...] tenho crise de tempo [...] para fazer tudo o que quero [...]", afirmava um dos jovens. Sobretudo, porque, "[...] eu acho que a escola devia ser uma parte, não nos devia ocupar tanto tempo de aulas, ou, se calhar, até devíamos ter mais, mas não nos devia obrigar a estudar tanto, a fazer tanta coisa sozinhos, [...].

'De facto, ao longo de algumas sessões foi notória a insistência na definição da relação estressante que, segundo alguns estudantes, era possivel acontecer entre a questão do tempo disponivel ou da sua ausência e a questão da necessidade de se aplicarem cada vez mais com vista à superação de avaliações negativas em algumas disciplinas, (mesmo daquelas de que não se gostava e, por isso, as que mais custavam a estudar) cada uma das quais, por si só, a exigir muito tempo de estudo: "É assim, para subir mais um valor temos de nos aplicar mais, mas temos que nos aplicar mais nessa, temos de nos aplicar nas outras todas e o dia não tem vinte e cinco horas, não é?[...] não chega para tudo [...]".

Neste sentido, a avaliação parecia assumir um papel de grande transversalidade, pois cruzava vários domínios, estivessem eles directamente ligados com projectos de vida, com objectivos traçados para o futuro, com pressões familiares ou, sobretudo, com a vida escolar, que se ia diluindo em estreita convivência com a vida juvenil, passada entre os portões da escola.

Aliás, como referiu uma jovem do $10^{\circ}$ ano do Curso Geral, a propósito dos objectivos a atingir no Ensino Secundário e dos projectos pessoais futuros que, para alguns, passavam normalmente pelo prosseguimento de estudos no Ensino Superior: "Nós chegamos ao secundário e já temos [...] algumas fronteiras que queremos atingir. [...] Metas. [...] Agora conta tudo, por exemplo, para o curso que queremos tirar que é o objectivo que queremos atingir".

Como se depreenderá destas palavras, a avaliação externa - os exames nacionais - assim como o peso variável da percentagem a ela associada $(30 \%, 50 \%)$ não deixava de ser sentida, por um lado, como um tempo crucial, porém, simultaneamente trágico, porque esquecia a avaliação interna realizada ao longo dos três anos 
de Ensino Secundário e, por outro, altamente prejudicial para a concretização dos projectos de alguns destes jovens conscientes de que " $50 \%$ é decidir a nossa vida quase em duas horas, o que é chato!".

"Vêem um tipo todo engravatadinho [...] Ministro da Educação a dizer tudo 0 que tu fizeste durante 12 anos só vale 50\% [...] E eu, possa!".

Embora, para muitos, a vontade e o esforço pessoal e o abdicar de viver a vida com os amigos e a família e as estratégias delineadas pudessem, de algum modo, facilitar a concretização das suas expectativas: "É só estudar mais um bocadinho, faltar uma ou outra vez ao treino".

Sendo assim, para alguns, o sucesso escolar parecia determinar que se esquecesse a vida juvenil fora da escola, pois o esforço pessoal, a abnegação e a força de vontade poderiam permitir derrubar barreiras para se atingir a meta desejada. No entanto, outros, embora concordando com esta perspectiva, não deixaram de lembrar alguns dos efeitos nocivos que podiam recair sobre alguns jovens, atendendo à pressão que sobre eles se impunha: "Se tens força de vontade, fazes. [Mas, por outro lado, o reverso da medalha não deixa de ser preocupante, pois] quando uma pessoa mete na cabeça que acha que consegue, começa a estudar, estudar, estudar e depois começa a [...] fogo, começa a stressar muito [...]".

No entanto, pareciam existir outras dimensões e sentidos que poderiam expressar não só a monotonia e o cansaço emocional de fazer sempre a mesma coisa diariamente, mas também a fadiga de andar na escola e de estar farto das rotinas escolares. Dilemas esses de onde parecia emergir o desespero de não estar contente consigo próprio e que a autocensura sublinhava. A reflexão transcrita a seguir poderá traduzir, de algum modo, a imagem de desilusão e de angústia de alguns jovens durante a sua escolaridade de nível secundário:

"[...] apesar de eu tirar as notas que tiro, eu estou farta da
escola, farta!" "Estou cansada de ser sempre a mesma coi-
sa. Chegar a casa, saber que tenho que estudar. Chegar ao
fim de semana e saber que tenho que estudar [...]. Às vezes,
ir para casa e não conseguir dormir [...] Eu chego ao ponto
de não conseguir dormir por causa dos testes. Vou para a
cama e ponho-me a pensar nos testes, não consigo dormir.
[...] Eu sou sempre assim porque tenho a mania de ser per-
feccionista em tudo e se eu não fizer perfeito, eu ralho
comigo própria, fico [...] passo-me completamente".
"E quando eu não consigo fazer as coisas como eu quero,
enervo-me".

Por vezes, no meio destes dilemas juvenis, um olhar mais atento para dentro de si próprio acabava por revelar, ainda, um mundo interior plasmado em frases singulares, 
onde coexistiam a censura e a autocrítica em virtude de não se sacrificar mais a vida pessoal e a vida juvenil em favor da vida escolar tendo em vista a avaliação que se pretendia obter: "Às vezes, devia sacrificar mais!'. Ou, ainda, por exemplo, quando a classificação do teste não correspondeu ao esperado, mesmo reconhecendo-se que algumas perguntas do teste não eram suficientemente explícitas e objectivas, a causa era procurada, tendencialmente, em si próprio, na falta de estudo, responsabilizada por o teste não ter corrido como se esperava. Pareceu ser este o entendimento que decorria da frase seguinte proferida por uma jovem do $10^{\circ}$ ano: "[...] não percebi lá muito bem 0 esquema que a professora fez, mas também foi falta de estudo, correu-me mal".

No entanto, como temos vindo a salientar, por um lado, para além dos apelos à autoconfiança e ao encorajamento e, por outro, ao reconhecimento de que a culpa recaía sobre si próprios, alguns destes jovens alunos revelaram-se bastante críticos, relativamente a uma prática recorrente que tem a ver com o facto de os testes de avaliação decorrerem durante o mesmo período de tempo em todas as disciplinas (a mesma semana), o que conduzia, do seu ponto de vista, a uma saturação intelectual e a um dispêndio de energia que acabava por não se traduzir em boas surpresas.

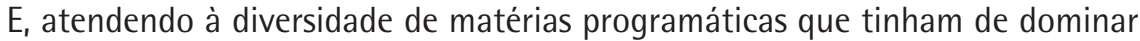
num curto espaço de tempo, iam reconhecendo que a vontade para estudar se ia esgotando na passagem dos dias. Ou, ainda, quando o esforço pessoal não era traduzido na classificação esperada, o desânimo, o desalento assumiam um papel determinante: Quando a gente tira boas notas e está o ano a correr bem, sentimonos bem. Agora quando não corre de modo [...] só negas, eu sinto-me mal.

"No outro ano, no $1^{\circ}$ período tinha-me esforçado e tirei 8. Fiquei desanimada".

Factos estes que, na opinião de uma estudante podiam chegar a influenciar, logo no início de um novo ciclo de estudos - o secundário - a anulação a determinadas disciplinas, dentre as quais a Matemática, à qual, muitas vezes, continuavam a estar associados os estigmas da frustração, do insucesso e do abandono.

Retomando as palavras de alguns destes estudantes, determinados motivos recorrentemente ligados à avaliação, e que fomos anotando, poderiam ter consequências (ir)reversíveis nas suas atitudes face às aprendizagens e às vivências escolares. Atitudes essas que, por sua vez, acabaram por se revelar através de diferentes manifestações onde para além do desalento e do desânimo, a disforia pós-testes ocupava um lugar de destaque, embora se admitisse, também, que este tempo de acalmia pudesse reverter em seu próprio desfavor:

"Eram muitos, uns em cima dos outros, depois com muito trabalho, depois não dá para estudar para todos e depois ainda por cima, para além das surpresas que temos nos testes [...] os professores pensam que a gente só tem a disciplina deles, não é? Depois 
não temos outra vida senão estudar para o teste e pronto. [...] Depois tem aquela coisa de que quando nós temos duas ou três semanas assim com muitos testes, a semana seguinte, a tendência é para nem mexer nos livros, uma pessoa não quer mesmo fazer nada, nada de nada. É o que apetece, mas aí... [...] depois as notas é que se lixam [...]".

Mas, apesar de todos os dilemas que alguns destes grupos de jovens deixaram transparecer na leitura que fizeram dos quotidianos escolares, do que puderam pensar e/ou dizer relativamente ao processo de avaliação interna e de avaliação externa que tinham de cumprir, em dadas ocasiões, também se mostraram entusiasmados porque tinham conseguido a "positiva" desejada e, ainda, combativos, exprimindo algumas opiniões favoráveis a medidas mais enérgicas e radicais relativamente à manutenção ou não dos exames nacionais.

Neste sentido, quando uma jovem pôs a hipótese, salientando, «eu acabava com os exames", deixou, em aberto, a possibilidade de os alunos serem avaliados, no final deste ciclo de estudos, "por tudo o que têm feito nesses três anos, [...] porque não é uma hora e meia, nem duas, [...] que vão decidir a nossa vida. [...] até porque nem todos os dias são iguais". Opinião que outro jovem corroborou explicitando o ridículo desta situação, particularmente quando a ela estava associado o denominado "trauma da medicina":

"Quer dizer, uma pessoa anda aqui doze anos e depois vai decidir tudo em duas horas, é assim um bocado ridículo. [Até porque] uma pessoa pode chegar à hora, ao exame, e estar mal disposto e correr-nos mal e depois estamos logo tramados, por isso [...]".

Através dos discursos proferidos e dos debates havidos notámos, particularmente, durante a realização dos grupos de discussão com o grupo do $11^{\circ}$ ano do Curso Geral, ter havido uma intersecção, que se afigurava com alguma recorrência e nitidez, entre a questão da avaliação e a problemática das médias imprescindiveis para o acesso a determinados cursos do Ensino Superior, sobretudo os directamente relacionados com a saúde, de que a medicina era o expoente máximo.

Da leitura que continuámos a fazer dos seus discursos, uma outra dimensão que, no nosso entender, se poderia associar ao stress provocado essencialmente pela avaliação e por alguns dos seus efeitos perversos, dizia respeito a um outro tipo de pressão, desta vez em sintonia com as expectativas familiares destes jovens e que eles acabaram por caracterizar.

Assim, à medida que avançávamos nos grupos de discussão, com alguma frequência os intervenientes traziam para o debate a questão da avaliação conectada ora com a percepção da relevância que o sucesso escolar provocava na família, ora com algumas das estratégias que a família podia gizar para favorecer as aprendizagens dos seus filhos, nomeadamente recorrendo à repreensão e à chantagem. 
Neste sentido, nomeadamente o pai e/ou a mãe, atribuindo à avaliação uma relevância enorme para o futuro dos filhos pareciam encarar outras hipóteses que pudessem minimizar ou mesmo resolver os problemas de insucesso que afectavam os seus educandos. Segundo os nossos interlocutores, se, por um lado, davam "raspanetes", por outro, estabeleciam um "contrato" que poderia ratificar, de algum modo, num futuro próximo, qualquer decisão menos agradável que pudessem vir a tomar, se entretanto a avaliação dos seus educandos não viesse a corresponder às suas expectativas. Foi o que se poderia depreender das seguintes opiniões expressas e corroboradas por algumas jovens alunas do $10^{\circ}$ ano:

"Os meus pais não me castigam pelas notas, dão-me é um raspanete que acham que devia ter feito melhor ou coisa do género".

"Ela, este ano ainda não deu raspanete por causa das notas. Diz é que acha que eu, se calhar, que eu, às vezes, que estudo pouco [...]. Agora noutros anos, ela dava assim mesmo raspanetes grandes se tirasse, por exemplo, suficiente ou coisa do género, que não tinha jeito nenhum, não sei quê".

"A minha mãe não me castiga muitas das vezes, mas dá-me raspanetes".

Efectivamente, este nosso estudo apresentou-se bastante revelador das preocupações intrínsecas às famílias no que respeitava, sobretudo, às aprendizagens tendo em vista o prosseguimento de estudos e o seu futuro profissional. Poderíamos, eventualmente, ser levados a pensar que estas atitudes familiares se desenvolviam e se acentuavam junto dos jovens que seguiam o primeiro Agrupamento, CientíficoNatural, que dava acesso a cursos superiores muito privilegiados (medicina, engenharia), mas não nos pareceu que essa hipótese correspondesse à realidade, pelo menos àquela que os nossos interlocutores nos deram a conhecer.

De facto, trabalhámos também com outro grupo de jovens, curiosamente todas do sexo feminino, que frequentavam o Curso Tecnológico de Administração e eram oriundas de famílias com parcos recursos económicos, de meios sociais desfavorecidos e com baixa escolaridade o que poderia fazer supor alguma indiferença familiar relativamente à sua avaliação escolar.

Mas, apesar de alguns dos seus pais se encontrarem ausentes porque trabalhavam em países da União Europeia, e contrariando o que alguém, por distracção, poderia supor, algumas dessas jovens referiram o facto dos resultados escolares serem seguidos, atentamente, no seu meio familiar. Neste caso, a figura materna parecia assumir um papel extremamente relevante e uma dupla função, pois tanto podia exercer um controlo face à avaliação interna, como desenvolver estímulos positivos criando fortes expectativas para que, neste caso, as filhas terminassem o Ensino Secundário ou viessem a prosseguir os seus estudos, o que, no nosso entender, veio reforçar a ideia 
de que a conclusão de um curso secundário e a posse de um diploma podiam permitir mudar de vida e de estatuto social (mobilidade social ascendente).

Na nossa perspectiva, as passagens seguintes permitiram compreender melhor 0 que acabámos de mencionar, ou seja, os critérios subjacentes às atitudes das suas mães e, ainda, as razões explicativas para chegarem à compreensão do sentidos da insistência das mães quanto à conclusão do Ensino Secundário. Acima de tudo, não queriam que as suas filhas tivessem a mesma vida que elas:

"[...] Quando foi o ano passado, tirei oito negas, depois queria desistir. A minha mãe é que começou [...]: 'Não desistas, não sei quê' [...]".

"Se eu desisto da escola, sou uma mulher morta (...).A minha mãe o que ela quer é: fazer o $12^{\circ}$. Depois de fazer o $12^{\circ}$ posso fazer aquilo que eu quiser, ir trabalhar, estudar [...]".

"A minha mãe quer que eu siga. [...] Como nenhum dos meus irmãos seguiu, tenho de ser eu".

"Pois, elas não querem que a gente esteja em casa. Primeiro, estamos em casa a fazer nada, porque elas também estão em casa. [...] E depois, a minha mãe quer que eu tenha uma profissão. Que não seja igual a ela".

"E depois nos ver num emprego melhor do que elas estão. Porque elas estão em casa a ver-nos num emprego mais ou menos ficam mais felizes se a gente arranjasse um emprego melhor'.

"A minha mãe também diz que quer que eu siga e não sei quê, que arranje um emprego bom para não ficar depois dependente do marido [...] A minha mãe dizme mesmo [...] que não quer que eu seja como ela, que é dependente do meu pai. Ser dependente dum homem não dá certo, não sei quê. [...] Nós estamos em casa e depois, se o marido nos deixa ou quê? Ficamos sem nada? Se tivermos o nosso trabalho, se ele nos deixar, olha [...] deixou".

Assim sendo, face às perspectivas sobre a avaliação e o insucesso aqui delineados por estes diferentes grupos de jovens, pareciam existir sentimentos bastante fortes conotados com grandes desilusões relativamente aos resultados da avaliação conseguidos e que foram entendidos como graves falhas pessoais face às expectativas depositadas em si próprios e também pela família, os quais acabaram por ser assumidas como derrotas pessoais, nomeadamente, quando a avaliação não correspondeu ao esforço despendido e quando "[...] a gente está habituada a passar, e a esforçar-se, pelo menos eu, de vez em quando, passo até à meia-noite, meia-noite e tal e depois chego ali e tirar aquelas notas assim e dizer eu este ano vou ficar [...] primeiro ano [...] chau, não dá". 
Neste contexto, e no sentido de chegarmos à compreensão das atitudes de algumas destas jovens relativamente aos sentidos que podiam encontrar no facto de frequentarem um curso no Ensino Secundário sem sucesso, pareceu-nos que o mais fácil para algumas passava por uma espécie de autopenalização relativa. Isto é, se, por um lado, desistissem dos seus sonhos e abandonassem precocemente a escola, por outro, poderiam conservar quase intacta a sua autoestima.

Por vezes, e como atrás observavam, foram os elementos da família ou o namorado que desempenharam um papel preponderante para a sublimação e para a aceitação das suas maiores derrotas - as «negativas", no final do período e/ou a retenção no final do ano lectivo. Também, neste domínio, a família exerceu um papel preponderante de suporte, de incentivo para continuarem na escola com vista à conclusão com êxito do Ensino Secundário fazendo-as acreditar nas suas potencialidades: "[...] o meu pai é que disse que eu é que sabia. Eu é que tinha que escolher o meu futuro e se queria continuar na escola [...] Fazia muito bem em continuar".

\section{Conclusão}

Este estudo ao interessar-se pelo lado subjectivo e por aquilo que representou a frequência de uma escolaridade de nível secundário, numa altura em que a escola se aproximava de um quase-mercado educativo, permitiu encontrar alguns jovens alunos que à semelhança de outros, acabaram por aprender a combinar lógicas de acção para se integrarem na cultura escolar e construírem estratégias para a sua sobrevivência face à selecção e à avaliação escolares. Para que tal acontecesse, a responsabilização e a inter-ajuda desempenhavam um papel preponderante na construção do ofício de aluno.

Acrescente-se que, ao longo desta pesquisa parece evidenciar-se uma experiência escolar dolorosa, difícil, feita de dilemas e de ansiedades que alimenta os seus quotidianos e que parece não permitir a conciliação de dois universos dicotómicos - o mundo da vida juvenil e o mundo da vida escolar. 


\section{Referências}

ABRANTES, P. Os sentidos da escola: identidades juvenis e dinâmicas de escolaridade. Oeiras: Celta, 2003.

AFONSO, A. J. Relações de poder no quotidiano da escola e da sala de aula. Cadernos de Ciências Sociais, Porto, n. 10/11, p. 133-155, 1991.

A cultura social de discriminação e avaliação dos alunos do ensino básico, In: PACHECO, J. A.; ZABALZA, M. (Org.) A avaliação dos alunos dos ensino básico e secundário. Braga: UM, IEP, 1995.

BARRĖRE, A. Les lyceens au travail. Paris : PUF, 1997.

COLEMAN, J.; HUSÉN, T. Tornar-se adulto numa sociedade em mutação. Porto: Afrontamento, 1990.

CORREIA, J. A. Para uma teoria crítica em educação. Porto: Porto Editora, 1998.

CRUZ, B. A participação política da juventude em Portugal: as elites políticas juvenis. Análise Social. Lisboa, v. 25, n.105/106, p. 223-249, 1990.

CRUZ, B. et al. A condição social da juventude portuguesa. Análise Social, Lisboa, v. 20, n. 81/82, p. 285-308, 1984.

DUBET, F. L'école des chances: qu'est-ce qu'une école juste?. Paris: Seuil, 2004. . Les lycéens. Paris: Seuil, 1991.

Rôle et expérience. In : BARBIER, J. M. et al. L'analyse de la singularité de l'action. Paris: PUF, 2000.

DUBET, F. ; COUSIN, 0.; GUILLEMET, J. P. Sociologie de l'expérience. Paris: Seuil, 1994.

Sociologie de l'expérience lycéenne. Revue Française de Pédagogie. Paris, v. 94, p. 5-12, 1991.

DUBET, F. ; DURU-BELLAT, M. L'hypocrisie scolaire :pour un collège enfin démocratique . Paris: Seuil, 2000.

DUBET, F. ; MARTUCCELLI, D. À l'école: sociologie de l'expérience scolaire. Paris: Seuil, 1996. 
EVERHART, R. B. Leer, escribir y resistir. In: MAILLO, H. V.; JAVIER CASTAÑO, F.; ÁNGEL RADA (Org.). Lecturas de antropología para educadores. Madrid: Trotta, 1999.

GAMA, M. J. Contra o mito da 'Geração Rasca':as vozes de estudantes do $12^{\circ}$ ano do Ensino Regular Público. Lisboa: ME, DEB, 2003.

GOMES, C. Conflito e cooperação na escola secundária portuguesa: uma análise sociológica da interacção na sala de aula. Braga: UM, IEP, 1998.

GRÁCIO, S. Crise juvenil e invenção da juventude: notas para um programa de pesquisa, In: STOER, S. (Org.). Educação, ciências sociais e realidade portuguesa: uma abordagem pluridisciplinar. Porto: Afrontamento, 1991.

JACKSON, P. La vida en las aulas. 2. ed. Madrid: Morata, 1992.

LIMA, L. C. A escola como organização e a participação na organização escolar. Braga: UM, 1992.

Gestão das escolas secundárias:a participação dos alunos. Lisboa: Livros Horizonte, 1988.

LOPES, J. T. Tristes escolas. Porto: Afrontamento, 1996.

MATOS, M. 0 ensino secundário: alguns dados dum 'novo mundo'. A Página da Educação, Porto, PT, v. 15, n. 154, mar. 2006a.

O Projecto JOVALES e a dupla crise do ensino secundário. Porto, $2006 \mathrm{~b}$. Mimeografado.

MAYORAL, D. Diferenciación y desigualdade: cuando las diferencias culturales se conviertem en desiguldades sociales. Revista de Educación, Madrid, v. 311, p. 183-202, 1996.

PAIS, J, M. Culturas juvenis. Lisboa: Imprensa Nacional: Casa da Moeda, 1993. . Emprego juvenil e mudança social: velhas teses, novos modelos de vida. Análise Social, Lisboa, v. 26, n.114, p. 945-987, 1991. Ganchos, tachos e biscates: jovens, trabalho e futuro. Porto: Âmbar, 2001. 
PAIS, J. M. Grupos juvenis e modelos de comportamento em relação à escola e ao trabalho: resultados de análises factoriais. In: CABRAL, M. V. V.; PAIS, J. M.

(Org.). Jovens portugueses de hoje. Oeiras: Celta, 1998.

. Lazeres e sociabilidades juvenis: um ensaio de análise etnográfica. Análise

Social, Lisboa, v. 25, n. 108/109, p. 591-644, 1990.

PERRENOUD, P. Ofício de aluno e sentido do trabalho escolar. Porto: Porto Ed., 1995.

POMEROY, E. The teacher-student relationship in secondary school: insights from excluded students. British Journal of Sociology of Education, London, v. 20, n. 4, p. 465-482, 1999.

RAYOU, P. La cite des lycéens. Paris: L'Harmattan, 1998.

ROCHEX, J. Y. Le sens de l' experience scolaire. Paris: PUF, 1998.

SANTOS, M. L. Políticas culturais e juventude. Análise Social, Lisboa, v. 26, n. 114, p. 991-1009, 1991.

SCHMIDT, L. Jovens: família, dinheiro, autonomia. Análise Social, Lisboa, v. 25, n. 108/109, p. 645-673, 1990.

TAVARES, D. S. D. A. O superior oficio de ser aluno: integrar(-se) para viver (n)a universidade. 2004. Tese (Doutoramento) - Faculdade de Psicologia e de Ciências da Educação, Universidade do Porto, Porto, PT, 2004.

Recebido em: 12/03/2010

Aceito para publicação em: 28/06/2010 